\title{
Millimeter Wave Point to Multipoint for Affordable High Capacity Backhaul of Dense Cell Networks
}

\author{
François Magne \\ When-AB \\ Paris, France \\ fmagne@when-ab.fr
}

\author{
Antonio Ramirez \\ Fibernova Systems SL \\ Valencia, Spain \\ aramirez@fibernova.com
}

\author{
Claudio Paoloni \\ Lancaster University \\ Lancaster, UK \\ c.paoloni@lancaster.ac.uk
}

\begin{abstract}
The economic impact of millimeter wave wireless networks is a key parameter for the future deployment of novel high capacity network architectures. The future deployment of high density small cells needs a flexible and affordable backhaul. The techno-economic analysis of two different wireless backhaul architectures at millimeter waves, in Point to Multipoint and Point to Point, will be discussed. The EU Commission $\mathrm{H} 2020$ TWEETHER "Travelling wave tube based W-band wireless networks with high data rate distribution, spectrum \& energy efficiency" project aims to realize the first Point to Multipoint backhaul system at $\mathrm{W}$-band $(92-95 \mathrm{GHz})$ to providing a costeffective solution for new generation networks. This paper will discuss and demonstrate the advantages of millimeter wave Point to Multipoint in term of Total Cost of Ownership and flexibility of deployment.
\end{abstract}

Keywords - backhaul, mm-waves, TCO, small cells, 5G, economy, TWEETHER

\section{INTRODUCTION}

The general consensus is that innovations in connectivity and data distribution bring great benefits in national economies and societies. The advent of a new generation of high capacity mobile networks $(5 \mathrm{G})$ is considered a key enabler for a new digitalization era. Governments and institutions are already working to provide adequate infrastructures, encouraged by the numerous predictions of the high positive impact that $5 \mathrm{G}$ will have over the global economy. An addition of nearly 3 trillion dollars to the Gross Domestic Product (GDP) by 2035 is estimated only for the US. In Europe, studies have shown that full implementation of the Digital Agenda for Europe would increase European GDP by 5\%, or $1500 €$ per person, by 2020 [1- 7].

In terms of fixed broadband, optical fibres are today the main vehicle of high speed connection due to the huge capacity they are able to carry. However, fibre links have a high cost of deployment, and additionally need specific permits to be deployed in urban areas and not all the places allow fibre deployments. Openreach (UK) has been consulted upon an aspiration to conduct a large-scale Fibre to the Premises (FTTP) deployment, targeting 10 million premises by around 2025. The estimated cost is $£ 300-£ 600$ per location passed (total of between $£ 3$ bn to $£ 6$ bn) plus $£ 175-£ 200$ per premise to connect [6].

The project has received funding from the European Union's Horizon 2020 research and innovation program under grant agreement no 644678 .
On the other hand, the wireless distribution of data is overcoming the data transmitted by fixed access due to the popularity in the adoption of wireless terminals, mainly smartphones, but also tablets and laptops. At the end of 2016, $3 \mathrm{G}$ and $4 \mathrm{G}$ technologies accounted for $55 \%$ of global mobile broadband connections (excluding machine-to-machine, M2M), with 4 billion connections, while it is forecasted that the number of $5 \mathrm{G}$ connections will reach 1.2 billion by 2025 , accounting for around $14 \%$ of total connections excluding M2M [8-10].

$5 \mathrm{G}$ is an unstoppable process to provide users and industries with the capacity for a high quality and reliable experience that is already producing new economic models open to new operators. The challenge that the new generation of mobile wireless systems poses, due to the huge usage of data, can be only addressed by the allocation of new spectrum bands and the deployment of dense small cell networks in high demand areas, which, as observed in the case of $4 \mathrm{G}$ deployments, will require innovative solutions in the backhaul of high density small cells, e.g. with diameters as low as $50 \mathrm{~m}$. The multigigabit capacity needed to be fed to and by the small cells, the spectrum availability, the agility to reconfigure against traffic demands, the flexibility to assign frequencies to new operators and the environmental impact remain also open questions of the small cell deployments.

Wireless backhaul is a cost effective and flexible solution due to the low Total Cost of Ownership (TCO) and the substantial growth perspective [11-15].

Wireless backhaul needs wide frequency band to assure high capillary multigigabit capacity. The millimetre waves $(30-300$ $\mathrm{GHz}$ ) is the region of the spectrum that offers a numerous wide frequency bands suitable for the purpose. The technology for the radio is quite advanced below $90 \mathrm{GHz}$, with multigigabit data rate, however, the transmission power is still too low in comparison to microwaves and high directivity antennas are necessary. This determines that only Point to Point (PtP) links are presently available in the market above the Q-band $(40 \mathrm{GHz})$ [16]. Most of the links are PtP at V-band (around $60 \mathrm{GHz}$ ) and E-band (71 - $76 \mathrm{GHz}$ and $81-86 \mathrm{GHz})$.

PtP links are surely effective for connecting different sites wireless. Differently, when tens or hundreds of cells per $\mathrm{km}$ square have to be backhauled, the PtP architecture presents a relevant issue in terms of footprint and number of front ends. 
The Point to Multipoint (PmP) distribution has the intrinsic advantage that permits to link $\mathrm{N}$ sites by using only one transmission hub for $\mathrm{N}$ terminals, instead of $2 \mathrm{~N}$ front ends as in case of PtP. The transmission hub distributes the signal by a low gain antenna, to cover a sector of specific aperture angle and areas, to serve an arbitrary number of small cells. On the other hand, the use of a low gain antenna implies the need of high transmission power, not available at millimetre waves by solidstate amplifiers.

The European Commission Horizon 2020 project TWEETHER "Travelling wave tube based W-band wireless networks with high data rate distribution, spectrum \& energy efficiency" aims to the fabrication of the first Point to multipoint system, above $40 \mathrm{GHz}$, at W-band (92 - $95 \mathrm{GHz})$ for backhaul of small cells and fixed access [17][18]. The TWEETHER system is presently in the final fabrication phase. The system is based on a transmission hub equipped by a low-gain antenna to cover sectors up to $90^{\circ}$ aperture and $1 \mathrm{~km}$ radius. The transmission hub is powered by a new generation high-power traveling wave tube (TWT), that provides around $40 \mathrm{~W}$ transmission power, level not achievable by solid state device technology.

The TWEETHER system will enable a flexible and costeffective deployment of small cells and fixed access. Indirect potential benefits coming from TWEETHER can be measured in efficiency gains of European economy making use of wireless digital services, improved quality of life of EU citizens, and higher revenues in the ICT industry itself. A significant part of this welfare gain relies on the wireless ecosystem; therefore, presumably deriving from implementation of high capacity wireless systems. The TWEETHER system has two main commercial exploitation targets: one is the rapidly growing market of small cell backhaul, the second is the new market of fixed high-speed broadband access.

TWEETHER W-band PmP system aims to achieve a privileged position to meet the challenges of the small cell backhaul market due to its high-capacity performance, up to 10 $\mathrm{Gbps} / \mathrm{km}^{2}$ and expected cost.

In the following sections, a scenario study and technical economics analysis will be given based on Capital Expenditure (CAPEX), Operational Expenditure (OPEX), and Total Cost of Ownership (TCO).

\section{SCENARIO}

\section{A. The small cell challenge}

The small cells are a fundamental component of the new $5 \mathrm{G}$ networks. The challenge is their implementation when high cell density is needed. The modality of backhaul of dense cell deployment will determine the future of the architecture. The needed multigigabit per second capacity cannot be achieved only by fiber, but by a combination of fiber and wireless backhaul. New generations of users are using smartphones as small connected computers with increasing bandwidth request. This is only one of the main challenges for the new networks.

It can be addressed both by use of light licensed frequency bands and by millimeter waves, e.g. E-band in PtP, and millimeter wave Point to multipoint.

TABLE I

TOTAL COST OF OWNERSHIP

CAPEX

\begin{tabular}{|c|c|}
\hline Equipment + Margins & Site leasing \\
\hline Ancillaries & Spectrum leasing \\
\hline Installation and & Network operation and \\
Commission & Maintenance \\
\hline Planning \& & Power \\
Management & \\
\hline
\end{tabular}

\section{B. Point to multipoint or Point to Point}

The backhaul of dense small cells needs a high number of high capacity links in a restricted area. Two distribution scheme can be used, Point to multipoint (PmP) and Point to Point (PtP), independently of the small cell architecture (LTE, MIMO, etc.) (Fig.1).

The systems available in the market are mostly PtP, e.g. Vband links and E-band links. A PmP at Q-band has been recently

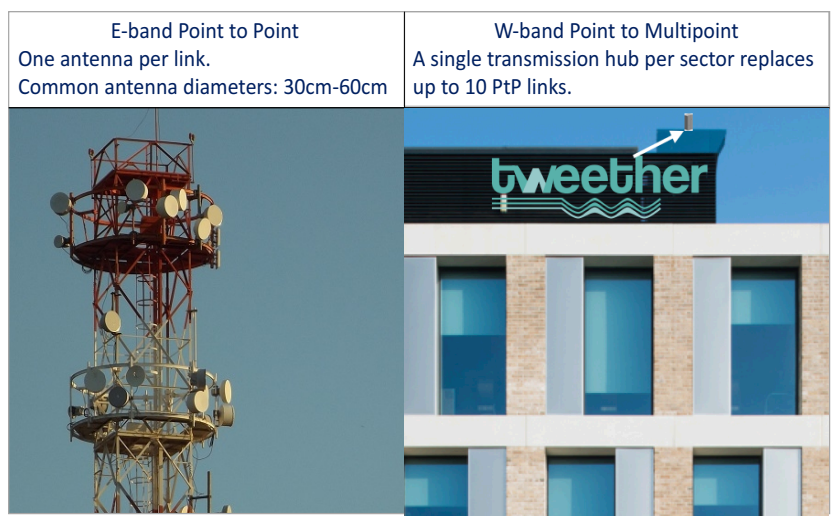

Fig. 1 Point to Point [20] vs. Point to Multipoint

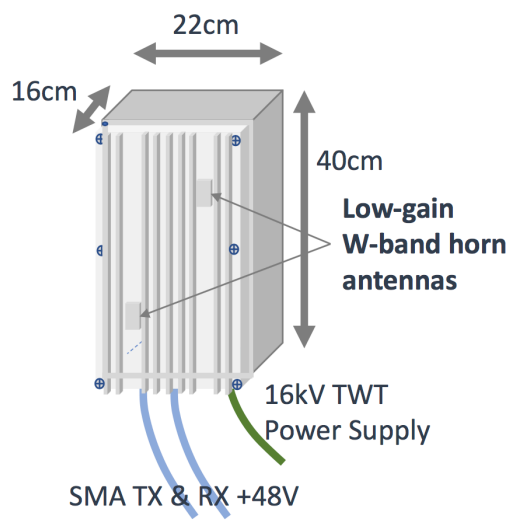

Fig.2 TWEETHER transmission hub 
presented (1 Gbps) [19]. The PmP W-band TWEETHER system is in the final phase of realization.

The comparison in terms of economy of the system is related to obvious components as the cost of electronics, the cost of sites and installation, but also to the environmental impact.

In particular, the footprint of the antennas system could be an obstacle to the deployment if too large. Fig. 1 shows the comparison of footprint of typical E-band PtP front end and Wband PmP for 10 cells. The dimension of the transmission hub in PmP is a fraction of the total footprint of $10 \mathrm{PtP}$ frontend.

\section{TWEETHER SYSTEM: SPECIFICATIONS, DIMENSIONS AND COSTS}

The TWEETHER system is based on a Transmission Hub (TH) and a number of Network Transmission Equipment (NTE) to connect the Base stations (BSs) or Point of Presence (PoP).

a) System main specifications:

- Operating frequency $92-95 \mathrm{GHz}$

- Area covered: sector

- Sector Aperture: $22^{\circ} / 45^{\circ} / 60^{\circ} / 90^{\circ}$

- Range: up to $1 \mathrm{~km}$

- Bandwidth per operator (prediction): $1 \mathrm{GHz}$

- Channel per operator: 10 with $40 \mathrm{MHz}$ bandwidth

- Modulation scheme: 64 QAM

- Capacity density: up to $10 \mathrm{Gbps} / \mathrm{km}^{2}$.

b) Dimensions outdoor units:

- Transmission Hub dimensions are 400 × 220 x 160 $\mathrm{mm}$ for a volume of $14 \mathrm{dm}^{3}$.

- Network Terminal Equipment dimensions are 250 x $150 \times 160 \mathrm{~mm}$ for a volume of $6 \mathrm{dm}^{3}$.

c) Price of outdoor units

The cost of the full equipment is still not confirmed, due to the development phase, but it could be assumed as worst case the pre-series cost.

- Transmission Hub $€ 34600$ (first 100 pieces)

- NTE $€ 2336$ (first 1000 pieces).

The given figures will be used for the economic analysis to demonstrate the advantage of the PmP distribution.

\section{B. PmP vs. PtP for dense cell deployment}

The goal of the techno-economic analysis is to individuate the most viable route to foster the process of cell densification. One vision is to deploy only cells at street level. It will be an effective option, but surely limited to specific areas, where cells will overlap for the coverage at street level. It needs specific permissions. Most of the cells will surely continue to be deployed at roof level.

This techno-economic model to compare $\mathrm{W}$-band PmP and E-band PtP is based on the computation of the Total Cost of Ownership (TCO) for both solutions in a dense cell scenario. It will compare 6-sectors $\mathrm{W}$-band $\mathrm{PmP}$ with 10 terminals per sector vs. equivalent 60 E-band PtP links. TCO takes into account both CAPEX amortized 10 years and the OPEX costs for 5 years maintenance.

\section{1) $C A P E X$}

The CAPEX (Table I) is the price of equipment (with vendor margin) plus the installation and commissioning, the initial investment for planning and management the site acquisition (administrative), the site survey and the project management.

The CAPEX for NTE terminal is $€ 3.2 \mathrm{k}$ (Fig. 3). The CAPEX for the TH, assuming six sectors is $€ 260 \mathrm{k}$ (Fig.4). Each sector includes an outdoor unit (ODU) with a TWT and an indoor unit (IDU).

Assuming that each sector covers 10 NTE, a total of 60 cells is backhauled, and the total CAPEX is $€ 450 \mathrm{k}$ (Fig. 5).

2) $O P E X$

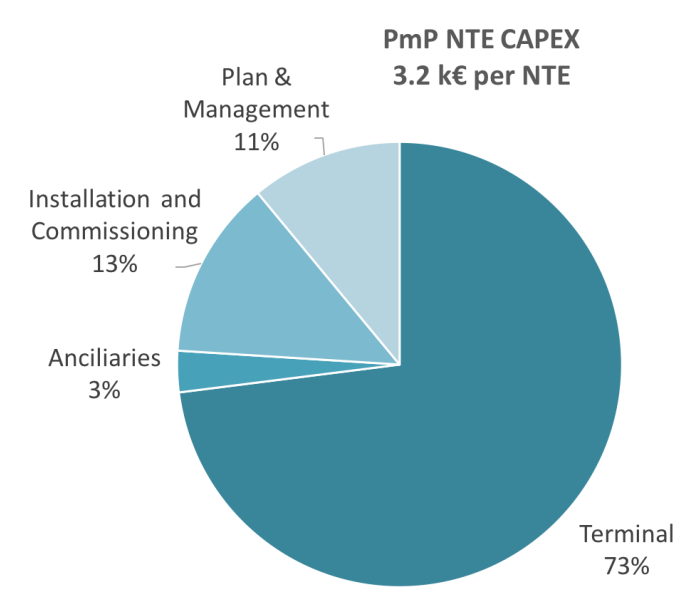

Fig. 3 CAPEX Network Terminal Equipment

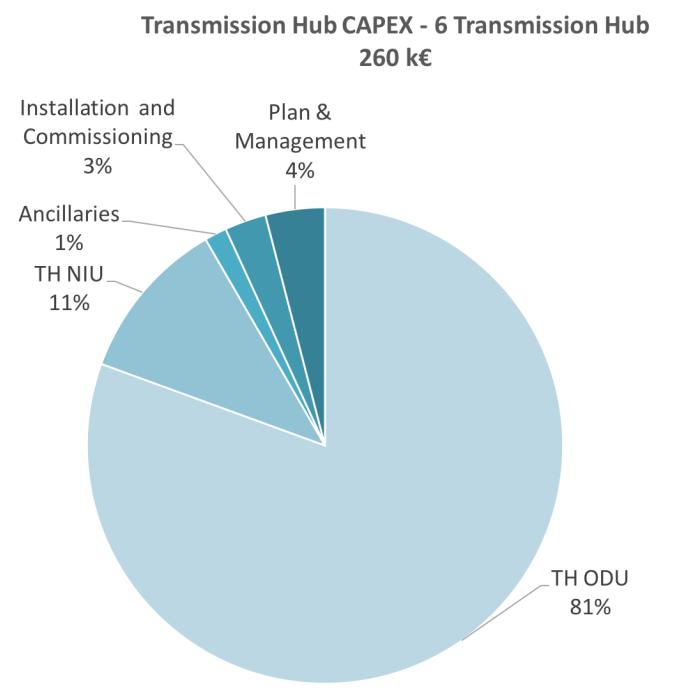

Fig. 4 CAPEX for Transmission Hub with 6 sectors (ODU Outdoor Unit) 


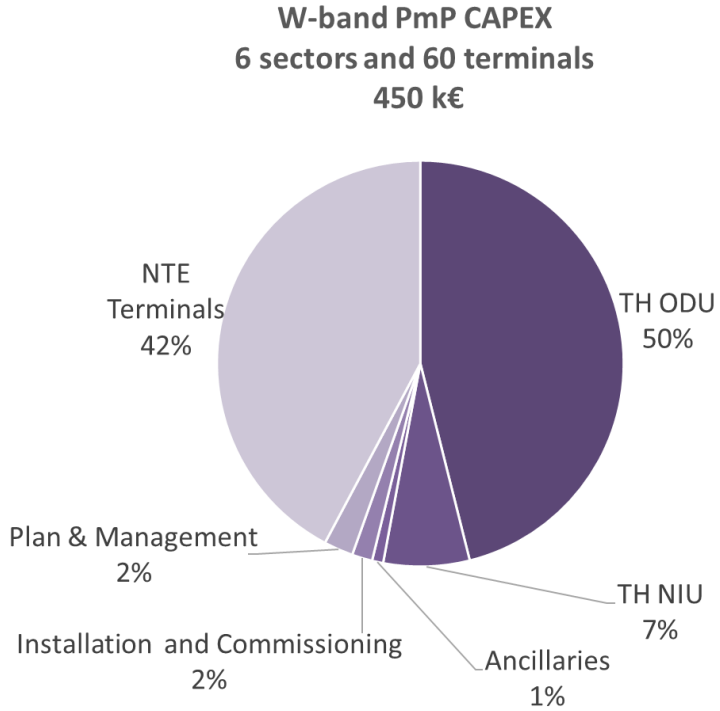

Fig. 5 CAPEX W-band 60 NTEs wireless backhaul

The calculation of the Operational Expenditure (OPEX) (Table I) is more complex since the site renting can be variable and an average has to be considered.

The Table II is shown an example of OPEX calculation for 6 sectors and 60 NTEs.

\section{Total Cost of Ownership}

The TCO for a Transmission Hub with six sectors with 10 cells each is $€ 938 \mathrm{k}$ as shown in Fig.6.

The chart in Fig. 6 shows that the site rental component is lower that the equipment cost.

\section{Comparison of PmP with PtP deployment}

In terms of high capacity (around $10 \mathrm{Gbps}$ per $\mathrm{km}^{2}$ ) only fibre optics or millimetre wave solutions can reach the required Mbps and density per users. Many analysts demonstrated that millimetre wireless PmP or PtP are competitive with fibre [11]. Fibre is deployed for infrastructure and fix access by $1^{\text {rst }}$ tier operators who can leasing capacity on their fibre to other operators. Therefore, for many operator wireless becomes the most viable economic solution. The main competitor to

\section{TABLE II \\ OPEX}

\begin{tabular}{l|r|r}
\hline Transmission Hub 6 sectors ODU + IDU & Y & 5 Years \\
Site Rental & $€ 23 \mathrm{k}$ & $€ 117 \mathrm{k}$ \\
60 NTE & & \\
Site Rental & $€ 44 \mathrm{k}$ & $€ 220 \mathrm{k}$ \\
Operation and Maintenance & $€ 23 \mathrm{k}$ & $€ 118 \mathrm{k}$ \\
& $€ 91 \mathrm{k}$ & $€ 456 \mathrm{k}$ \\
\hline
\end{tabular}

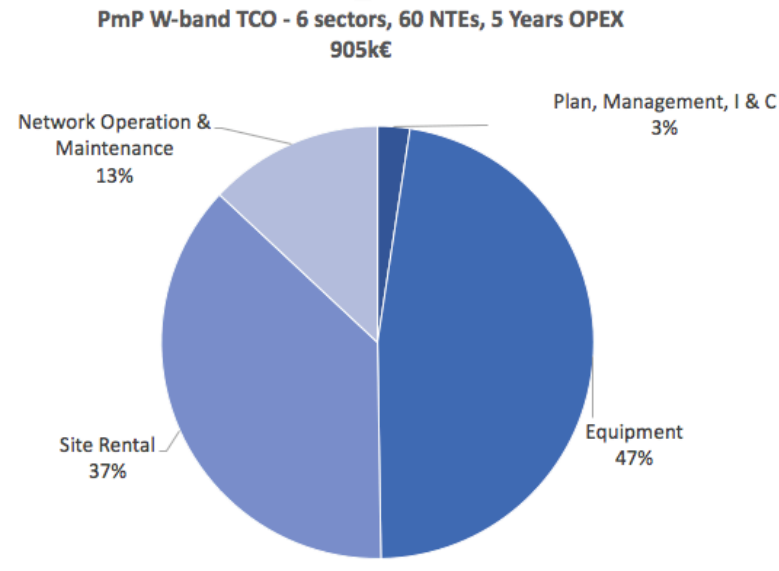

Fig. 660 NTEs PmP TCO

TWEETHER PmP is now PtP at E-band because it provides high capacity, has large spectrum and is now mature enough with many vendors providing lower equipment cost. The same TCO calculation performed for PmP in Section III, is performed in the Section IV for an equivalent PtP case at the E-band, with similar coverage of the TWEETHER system.

The equipment price is assumed the most affordable in the market. Using the same approach for the W-band PmP, the Eband CAPEX is $€ 532 \mathrm{k}$ as reported in Fig. 7.

For the OPEX, using the same parameters as for the CAPEX, it is obtained $€ 660 \mathrm{k}$ for site rental and $€ 143 \mathrm{k}$ for operation.

The breakdown of the TCO for the E-band case is shown in Fig.8. A total TCO of $€ 1335 \mathrm{k}$ results.

\section{DISCUSSION AND CONCLUSIONS}

The TCO comparison clearly shows the advantage of a PmP system over a PtP system for the same coverage. The OPEX is much affordable than the CAPEX. In addition, it has to be considered that the $\mathrm{W}$-band $\mathrm{PmP}$ has not yet the same maturity in the market as the E-band PtP. Substantial cost reductions will be achieved when large scale production starts. It is expected a

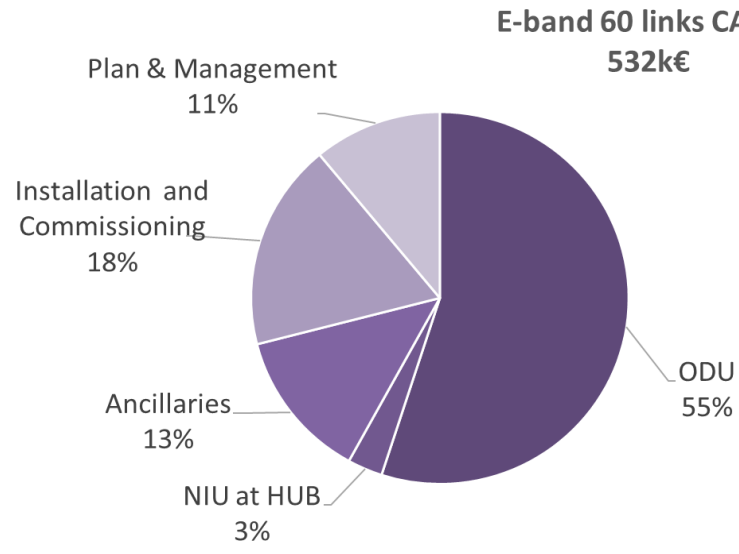

Fig. 7 E-band 60 links CAPEX 


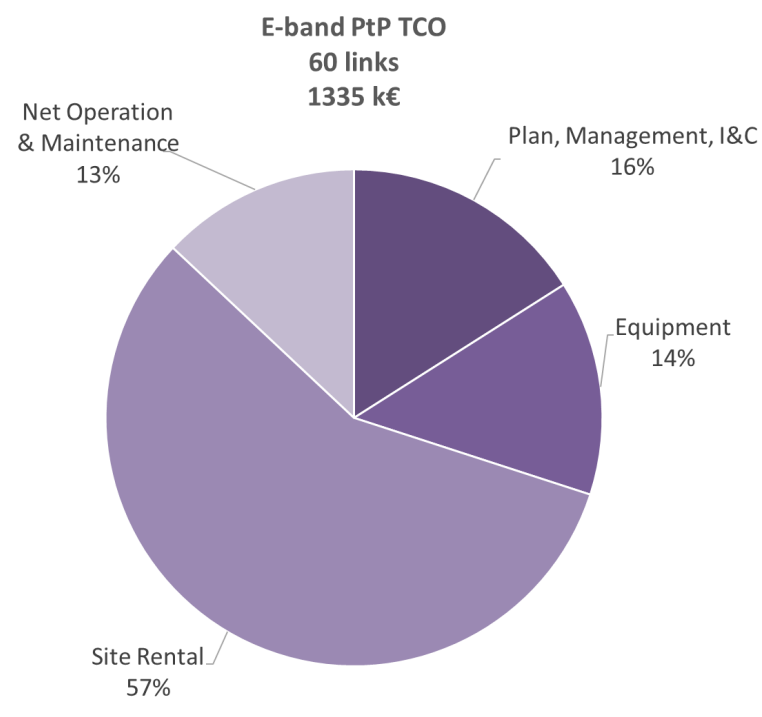

Fig. 8 E-band PtP TCO

reduction of the CAPEX. The OPEX, in both the cases, will follow the inflation.

E-band OPEX, as many analysts noticed, suffers of the number of sites and size of the products:

- $\quad$ Site leasing: the fees are proportional to the surface or volume occupied. The prices are variable with the countries and particularly higher in cities. In E-band PtP there is almost twice more equipment to install and their size is not less than 3-4 times bigger than $\mathrm{W}$-band

- $\quad$ Spectrum lease is already allocated at low cost for Eband, in UK, US or Spain. The price per year per link is basically of $€ 80$, but whereas there are many a couple of frequencies to manage the cost is around $€ 200$ if the operator sub-contracts the frequency acquisition and management to a specialised 3rd party.
- Network operating pertains to the current management of the network and its services as supervision, test, statistics, QoS... a 3\% factor of the equipment is used (instead of $2 \%$ in W-band) because of more complexity in the network architecture.

- Maintenance: a general percentage of 7 to $8 \%$ of the equipment cost is generally admitted, thus cheaper than the $9 \%$ in TWEETHER for which maintenance of the TWT every 5-10 years is foreseen (preventive maintenance).

Power consumption is not a very important part of the OPEX, for most constructors of E-band, a terminal would consume less than $50 \mathrm{~W}$.

What is not visible in the described process is the cost related to the deployment flexibility. The PmP permits to change position of a NTE without affecting the positioning of the Transmission Hub. Also, NTE can be added, without a planning, only on the basis of the capacity demand of the areas. Those are relevant features, fundamental for opening the market to new operators and new business models.

TWEETHER system has the capability to perform small cells backhaul (and also macro cell backhaul) on any city or on dense residential areas. The question is now to estimate which share could get TWEETHER based on the previous analysis. To this end, several weighting factors have been estimated pertaining to a preliminary exploitation plan.

- $\quad$ Time to market. The massive small cells deployment has not yet really started. Operators plan now a take-off in 2018.

- $\quad$ Areas addressed by TWEETHER are primarily Europe and US and part of EMEA (Europe, the Middle East and Africa) which represented $45 \%$ of the market, but less than $35 \%$ in the future.

- Proportion of the above areas in rainy ITU region higher than " $\mathrm{K}$ " lead to subtract $15 \%$ of the territories addressed.

- $\quad$ Proportion of wireless/fiber for new deployment could be around $75-80 \%$ because TCO of fiber is definitely more expensive.

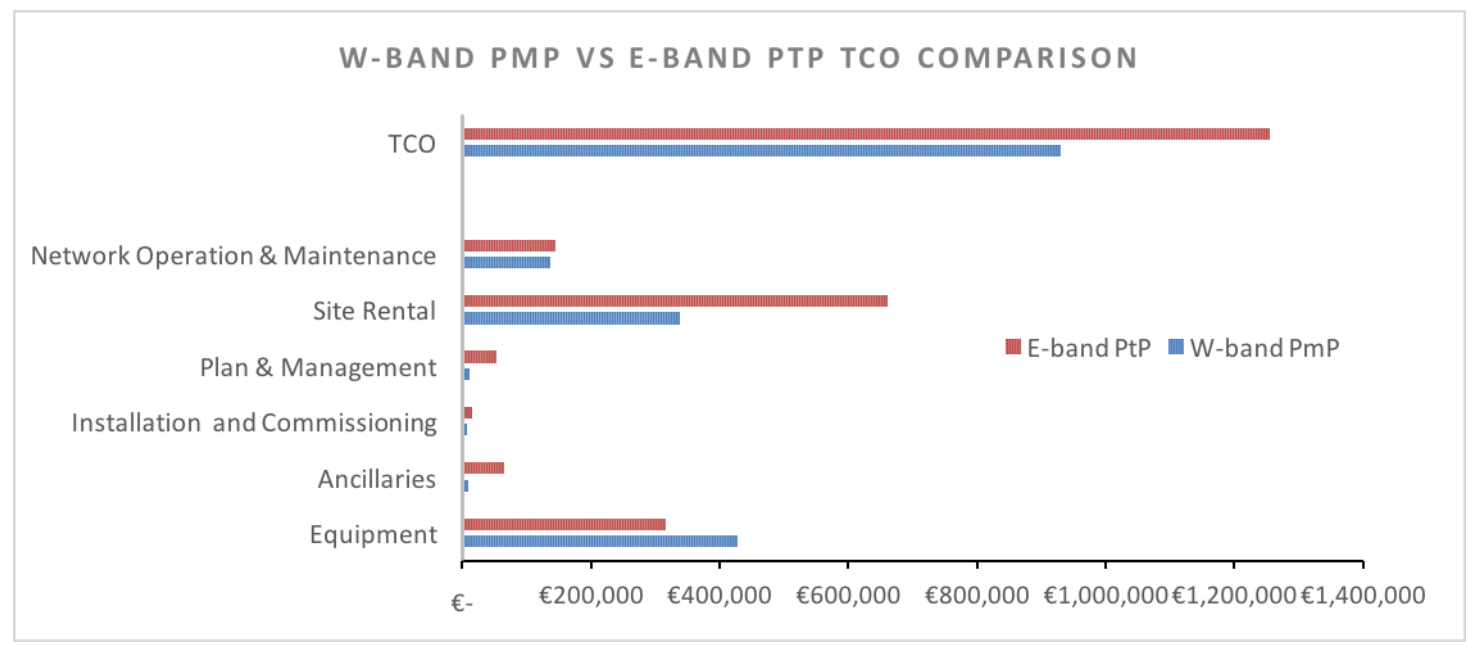

Fig.9. TCO comparison W-band PmP to E-band PmP. 
- Different analysts, including ABI Research [13], considers millimeter technology as the fastest growing technology, outpacing the overall market with a very high growth through 2020 . In particular, ABI Research predicts a $113 \%$ CAGR to reach a value of $\$ 668$ million and expects a combination of fiber-optic and mm-wave will represent approximately half of total backhaul links in 2019.

Finally, Fig. 9 shows a comparison chart between a deployment of 6 PmP sectors in W-band based on TWEETHER Project with 60 PtP links in E-band that summarizes the presented analysis. It is evident the impact on the site rental cost of the larger dimensions of PtP E-band system.

The techno-economic analysis presented highlighted the advantages of the novel Point to MultiPoint TWEETHER system, at 92 - $95 \mathrm{GHz}$, over the Point to Point distribution, for future millimeter wave backhaul networks.

\section{REFERENCES}

[1] https://www.gsmaintelligence.com/research/2017/08/5g-connections-tosurpass-1-billion-by-2025/636/

[2] Wireless Backhaul In Future Heterogeneous Networks, 2014 ERICSSON

[3] https://ec.europa.eu/digital-single-market/en/news/why-eu-betting-big5g-researcheu-focus-magazine

[4] https://www.qualcomm.com/invention/5g/economy

[5] http://europa.eu/rapid/press-release MEMO-12-1000 en.htm

[6] https://www.homeandbusiness.openreach.co.uk/

[7] https://www.cisco.com/c/en/us/solutions/collateral/serviceprovider/visual-networking-index-vni/mobile-white-paper-c11$\underline{\text { 520862.pdf }}$
[8] Mobile Economy Report 2017. GSMA Intelligence. https://www.gsmaintelligence.com/

[9] Delivering High-Capacity And Cost-Efficient Backhaul For Broadband Networks 2014 Ericsson

[10] Small-Cell Backhaul: Industry Trends And Market Overview 2013 SENZA FILI

[11] Total Cost Of Ownership And Time To Breakeven Of Last Mile Data Transport For Mnos And Isps -Real Wireless January 2016

[12] Small Cell Backhaul Biannual Update Business Models Analysis Report | PT-1529|2016 ABI -Research

[13] ABI Research - "Small Cells Surge At 43\% Compound Annual Growth Rate As Mobile Network Operators Densify Networks", Nov. 2015.

[14] R. Webb, "Small Cell Backhaul A 5-Year \$6.5 Billion Opportunity", HIS Infonetics, Dec. 2015.

[15] R. Webb, "Momentum Building In Millimetre Wave Market, Ignited By Outdoor Small Cells", IHS Infonetics, Oct. 2014.

[16] R. Vilar, J. Martí and F. Magne, "Point to multipoint wireless backhaul systems for cost-effective small cell deployment," European Microwave Conference (EuMC), 2015 European, Paris, 2015, pp. 1092-1095.

[17] Paoloni, C, Magne, F, Andre, F, Begaud, X, Krozer, V, Marilier, M, Ramirez, A, Vilar, R \& Zimmerman, R 2017, TWEETHER Future Generation W-band backhaul and access network infrastructure and technology. in European Conference on Networks and Communications (EuCNC 2017), Oulu, Finland, 11-15 June

[18] TWEETHER website [Online]. Available: http://www.tweether.eu

[19] http://cbnl.com/news/cbnl-unlocks-31 ghz-new-pmp-millimeter-wavesolution

[20] http://www.fiercewireless.com/tech/singapore-s-m1-huawei-achieve-35gbps-73-ghz-band 